\title{
Late Holocene Asian Summer Monsoon dynamics from small but complex networks of paleoclimate data
}

\author{
Kira Rehfeld • Norbert Marwan • Sebastian F. M. Breitenbach • Jürgen \\ Kurths
}

Received: date / Accepted: date

\begin{abstract}
Internal variability of the Asian monsoon 29 system and the relationship amongst its sub-systems, 30 the Indian and East Asian Summer Monsoon, are not ${ }_{31}$ sufficiently understood to predict its responses to a fu- 32 ture warming climate. Past environmental variability $з_{3}$ is recorded in Palaeoclimate proxy data. In the Asian 34 monsoon domain many records are available, e.g. from 35 stalagmites, tree-rings or sediment cores. They have to 36 be interpreted in the context of each other, but visual ${ }_{37}$ comparison is insufficient. Heterogeneous growth rates 38 lead to uneven temporal sampling. Therefore, computing correlation values is difficult because standard meth- ${ }^{39}$ ods require co-eval observation times, and sampling- ${ }^{40}$ dependent bias effects may occur.
\end{abstract}

Climate networks are tools to extract system dynamics from observed time series, and to investigate ${ }_{42}$ Earth system dynamics in a spatio-temporal context. We establish paleoclimate networks to compare pale- 43 oclimate records within a spatially extended domain. 44 Our approach is based on adapted linear and nonlin- 45 ear association measures that are more efficient than ${ }_{46}$ interpolation-based measures in the presence of inter- ${ }_{47}$ sampling time variability. Based on this new method we ${ }_{48}$ investigate Asian Summer Monsoon dynamics for the ${ }_{49}$ late Holocene, focusing on the Medieval Warm Period ${ }_{50}$ (MWP), the Little Ice Age (LIA), and the recent period ${ }_{51}$ of warming in East Asia. We find a strong Indian Sum- 52 mer Monsoon (ISM) influence on the East Asian Sum- ${ }_{53}$

K. Rehfeld · N. Marwan · Jürgen Kurths

Potsdam Institute for Climate Impact Research

P.O. Box 6012 03, D-14412 Potsdam, Germany

E-mail: rehfeld@pik-potsdam.de

S. F. M. Breitenbach

ETHZ Geologisches Institut, Climate Geology

Sonneggstrasse 5, CH-8092 Zürich mer Monsoon (EASM) during the MWP. During the cold LIA, the ISM circulation was weaker and did not extend as far east. The most recent period of warming yields network results that could indicate a currently ongoing transition phase towards a stronger ISM penetration into China. We find that we could not have come to these conclusions using visual comparison of the data and conclude that paleoclimate networks have great potential to study the variability of climate subsystems in space and time.

Keywords Asian Summer Monsoon · Complex Networks · Irregular Sampling • Little Ice Age . Medieval Warm Period

\section{Introduction}

Monsoonal precipitation dynamics and their possible change due to global warming are a matter of political and public concern in most of South-East Asia, and especially in India and China, as lives and prosperity depend critically on the monsoons' rainfall delivery [12, 28, 67. The Asian (Summer) Monsoon has shown abrupt changes in the past and its intensification (weakening) was likely concurrent with cultural prosperity (demise) 8, 9,68. The Asian monsoon system is comprised of two main sub-systems, the Indian Summer Monsoon (ISM) and the East Asian Summer Monsoon (EASM) (Fig. 1), both mainly driven by seasonal changes in the land-sea thermal contrast and related atmospheric pressure changes.

The Intertropical Convergence Zone (ITCZ) plays a governing role in monsoonal circulation and variations of its mean northward extent have been linked with summer monsoon strength 6, 18, 29, 49]. The defining geography (composition of landmass, mean altitude, 
position and extent of surrounding seas) however, isi15 quite different for ISM and EASM. The extent to which 116 the two sub-systems interacted in the past is a matter ${ }_{117}$ of current research $60,62,67,69,11$. As a third player,, 118 the mid-latitude westerlies dominate the area north and ${ }_{119}$ west of the (variable) monsoon boundary [11. The rela-120 tive strength of these circulation systems and thus theiri21 areas of influence, varied in the past [23, 35, 62, and 122 our knowledge about the complex spatio-temporal pro-123 cesses and variability behind them is insufficient [12]. ${ }_{124}$

Numerous paleoclimatological studies focused on the ${ }^{25}$ reconstruction of individual climatic parameters, such ${ }^{126}$ as moisture or precipitation $\left[5,32,38,39,47,62,67,66,,^{127}\right.$ temperature [66, or droughts [5, 12, 49,66] by use of ${ }^{228}$ proxy records. Furthermore, linkages among the Asian $_{129}$ Monsoon system and the North Atlantic realm $\left[22,24,{ }_{130}^{129}\right.$ 29, 63, 60, El Niño/ Southern Oscillation (ENSO) [46, ${ }_{131}$ and solar forcing $[21,61,68$, have been explored. However, the mechanism(s) and variability of the interac- ${ }_{133}$ tions between ISM and EASM during the Holocene (and beyond) remain far from being fully understood 61,67,62. Using numerical meta-analysis and recon- ${ }_{136}$ structions of moisture indices, Wang et al. found $\mathrm{an}_{137}$ asynchronous evolution of the ISM and the EASM for ${ }_{138}$ the Holocene on centennial timescales 62. The spatial distribution of the paleoclimatic records used in ${ }_{140}^{139}$ the study of Wang et al. did include only four records ${ }_{141}^{140}$ from India (out of a total 92) and focused mainly on ${ }_{142}$ China and Tibet, with no record in the ISM domain ${ }_{143}$ below $27^{\circ} \mathrm{N} 62$. It is important to note that the currently general low number of datasets from the Indian ${ }_{145}$ peninsula might lead to systematic biases towards the ${ }_{146}$ Tibetan plateau and China, complicating or even pre- ${ }_{147}$ cluding meaningful interpretation of results, a caveat ${ }_{148}$ that must be accounted for.

Based on ensemble runs of a coupled climate model ${ }_{150}$ run with anthropogenic forcing, May found an increase ${ }_{151}$ in monsoonal rainfall, accompanied by a decrease $\mathrm{in}_{152}$ the intensity of the overall lower-tropospheric large- ${ }_{153}$ scale circulation at a warming of $2^{\circ} \mathrm{C}$ relative to pre- ${ }_{154}$ industrial ISM conditions 34. Derived from global cli- ${ }_{155}$ mate modeling results and observations, an overall stag- ${ }_{-156}$ nation in precipitation but a redistribution towards ex- $^{-157}$ tremes (prolonged dry and wet spells) was supported $\mathrm{in}_{158}$ 28. Decreasing reliability of rainfall and increased vari ${ }_{-159}$ ability of precipitation amounts would have disastrous ${ }_{160}$ impacts on rain-fed agriculture all over Asia.

In the paleoclimatic context, we strive to under-162 stand whether the weakening of the large-scale circu-163 lation associated with a warming scenario, as found for ${ }_{164}$ the time period 2020-2200 AD in the modeling study by 165 May 34, is paralleled by an increased influence of the 16 ISM on the EASM domain during the MWP (1100-700 167 years BP) and during the recent warm period (RWP, 1850-1980 AD), in contrast to an expected diminished influence during the LIA (100-400 years BP). Given that the Asian Summer Monsoon is, amongst other factors, differential-heating driven, and thus modulated, to some extent, by northern hemisphere temperature, we hypothesize that the eastward ISM penetration depth was higher during periods of extended northern hemisphere warmth (e.g. the MWP) than during cool periods and vice versa. We define the boundaries of LIA (MWP) in agreement with the timings given by Jones et al. 26] and within the periods of relative cold (warmth) in the East Asian temperature reconstruction by Osborn \& Briffa 37.

On short (annual to multi-decadal) timescales, we are not aware of any study systematically investigating the interactions between both sub-systems. As we find that the understanding of any system is fundamental to comprehending its links to other systems, we aim to investigate the extent of interaction between the traditional ISM domain over continental India and the EASM domain over China. To this end we propose here the construction of paleoclimate networks, based on significant association between proxy records of past climate variability. Palaeoclimate records come with particularities, when compared to data used in climate network studies up to now. They are heterogeneously sampled in time (1) and space (2) which, if ignored, leads to biased and possibly incorrect results. Previous climate network studies have focused on the analysis of gridded datasets, from reanalysis data [16, 14, 20, 50, 58 65] or recent observations [19, 31,30 and were thus restricted to the recent, observational period. Palaeoclimate records are, in contrast, spatio-temporally inhomogeneously distributed. However, due to the increasing number of (Asian monsoon) records published in the last decades [62, the spatio-temporal reconstruction of past climates becomes feasible [12,62. In difference to previously analyzed climate networks, paleoclimate networks cannot make use of direct information about climate parameters (e.g. temperature) and have to rely on proxy data that are usually irregularly sampled in time and space. Generally, fewer datasets are available the further back in time the analysis is extended. Also, much less paleoclimate data is available from India, compared to China. One option would be to include only datasets that span all time periods of interest and an equal number from both regions of interest (ISM and EASM domain). However, this would decrease the robustness and significance of the results. Therefore, we strive to sample all regions consistently in order to retain comparability for different time slices, and include all records in the database where they meet 


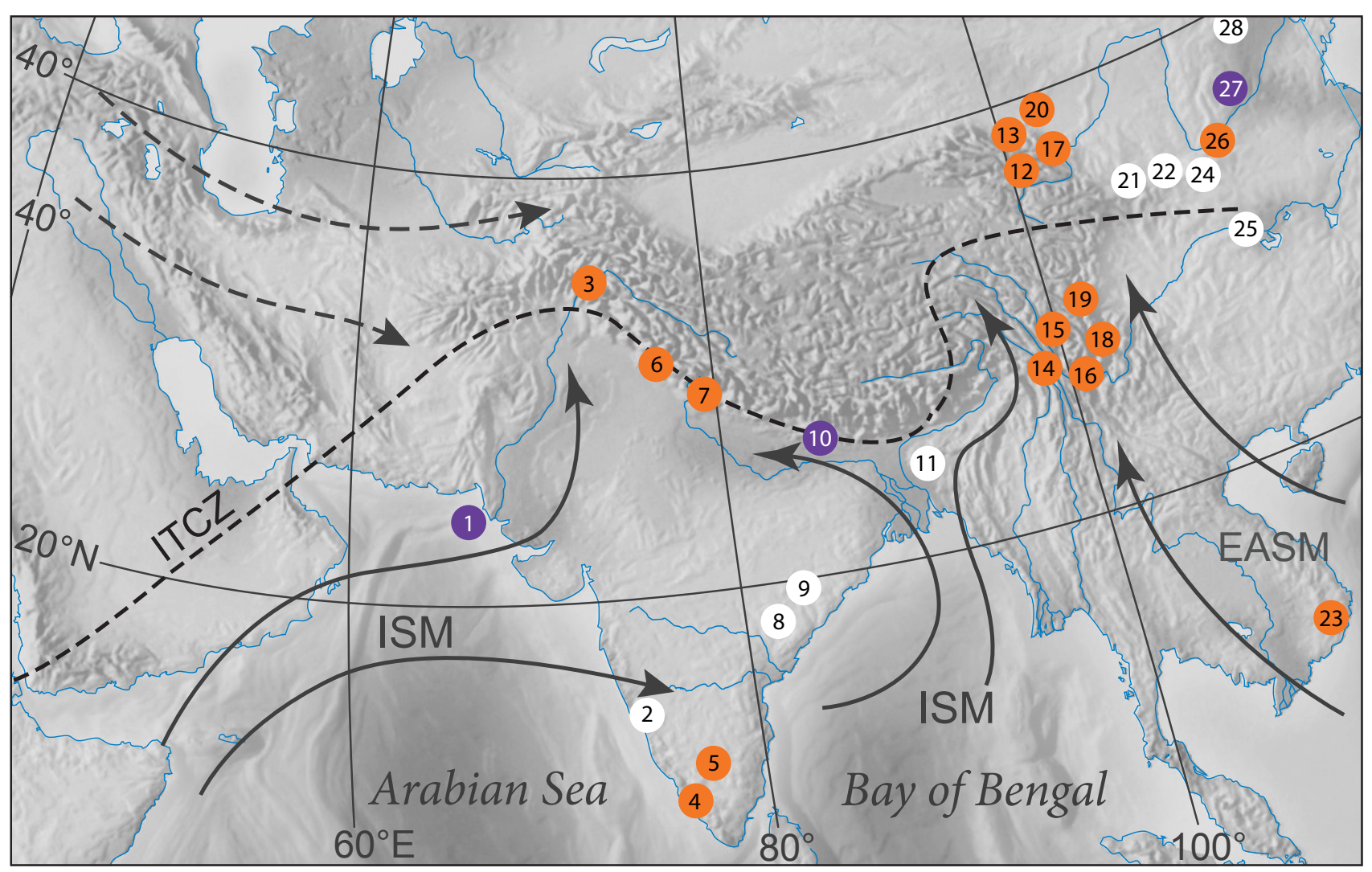

Fig. 1: Study area with generalized summer wind directions of the ISM and EASM (gray arrows), the westerlies (dashed arrows), as well as the spatial coverage of the records considered in the paleoclimate networks. Numbers of the nodes were assigned according to the longitude of the respective study site and furthermore refer to the entries in Tab. 1. Sites that are at close proximity might show displaced to prevent overlap of the dots and labels. Colors of the dots indicate the type of archive: orange - tree sites, white - stalagmites, purple - other archives (marine sediment (1), ice core (10), reconstruction using historic documents and tree ring data (27)).

the temporal sampling requirements. Possible bias ef-187 fects should nevertheless be kept in mind for the sub-188 sequent analysis and need to be discussed.

To improve spatial resolution and robustness of the estimates with increasing node numbers, we forsake the ${ }^{191}$ reconstruction of direct physical flows (which would ${ }^{192}$ limit us to using only precipitation or temperature re- ${ }^{193}$ constructions), but instead combine records of precip- ${ }^{194}$ itation and temperature. We argue that temperature ${ }^{195}$ and precipitation amounts over land covary, as the mois- ${ }^{196}$ ture-carrying capacity of atmospheric flows increase with ${ }^{197}$ temperature. We do not claim that the relationship, es- ${ }^{198}$ pecially in monsoonal and tropical climate, co-varies in ${ }^{199}$ a strict linear correlation sense either positively or neg- ${ }^{200}$ atively, but that a (nonlinear) association between the ${ }^{201}$ climate variables probably exists. Trenberth et al. found ${ }^{202}$ a negative correlation between monthly mean anoma- ${ }^{203}$ lies of boreal summer (MJJAS) surface air tempera- ${ }^{204}$ ture and precipitation amount of reanalysis data (1979-
2002) over much of India and China and state that "neither precipitation nor temperature should be interpreted without considering the strong co-variability that exists" [55]. Therefore, until a higher density of records for individual climate parameters is established, we believe it is justified to use both to reconstruct the flow of dynamical information, measured by the extent of linkages, significant associations, between the time series of individual nodes. Combining different archives increases the robustness of the analysis against individual archive-specific biases, e.g., trees might provide information where stalagmites cannot or vice versa. In contrast to other analysis methods, every node retains its individuality in the network and its role in the final result, the network, can be assessed both visually (e.g. in force-weighted network representations) or quantitatively (by computing network statistics). Furthermore, should incompatibility be suspected, node re- 
moval is straightforward and does not require re-compu-253 tation of the whole network.

Using published paleoclimate records from the $\mathrm{ASM}_{255}$ domain, we analyze late Holocene Asian monsoon dy-256 namics during the MWP, the LIA, and the recent warm 257 period (RWP, here: 1850-1980 AD). We review litera-258 ture and methodology of complex (climate) networks259 in Subsect. 2.1. In Subsect. 2.2 we then set out to260 document paleoclimate network construction and intro-261 duce linear and nonlinear similarity measures adapted262 to paleoclimate data. We describe the ASM paleoclimate data in Sect. 3 and the results we obtain from the paleoclimate networks in Sect. 4. In Sect. 5 our results ${ }^{263}$ regarding the Asian monsoon synchronization for the past millennium are compared to previously published ${ }^{264}$ findings and we discuss the robustness and advantages of the paleoclimate network approach compared to the usually employed visual comparison.

\section{Methods}

We propose a new, complementary tool for the recon-271 struction and investigation of spatio-temporal dynam-272 ics of climate systems in the past: Palaeoclimate net-273 works. The approach is inspired by climate networks ${ }^{274}$ which are a relatively new, but a powerful and increas ${ }^{275}$ ingly popular tool to reconstruct Earth system dynam-276 ics. In the following we first describe climate networks ${ }^{277}$ and subsequently develop the paleoclimate network ap-278 proach.

\subsection{Climate networks}

Climate networks are a relatively new tool to explore 284 spatio-temporal variability of climate parameters and $\mathrm{d}_{25}$ assess dynamical information flow between spatially dis-286 tant regions [16,14,31] and the stability of the climate 287 system and its teleconnections $[20,50,57,65]$. They are28 inspired by complex networks theory, which, from soci-289 ology through gene networks to citation networks con-290 sist of two main components: nodes, or vertices and 291 links, also called edges. The nodes might be represent-292 ing actors, genes, or authors of scientific papers. The293 links can be drawn from co-starring in the same movie,294 sequential expression of genes, or co-authorships. 295

Climate networks are based on observations of cli-296 mate dynamics (time series) at certain points, the nodes297 Computed from these time series, pairwise similarity298 calculation (linear correlation or nonlinear interrelation\$s99 like mutual information (MI) 15 or recurrence-basedsoo measures [17) yield a correlation matrix with entries301 for each pair of nodes. This matrix is then thresholded302 using either a fixed value for the correlation or a prescribed link density. The resultant adjacency matrix $\mathbf{A}$ is a sparse binary matrix with the $i, j$ th entry being nonzero if and only if the time series representing nodes $i$ and $j$ are significantly associated. Network statistics can subsequently be employed to assess overall characteristics of the network such as the degree distribution (e.g., how many links do the individual nodes have) or more abstract measures such as betweenness, where information flow through the network is quantified.

\subsection{Palaeoclimate networks}

\subsubsection{Difference to recent climate networks}

Major difference between modern observational or reanalysis data and proxy data is the heterogeneous sampling of the paleoclimate records. Whereas modern observations are represented regularly, hourly, daily, or monthly, many paleoclimate proxies are reconstructed with sampling intervals (e.g. from stalagmites or ice cores), varying intrinsically from sub-annual to centennial resolution. By nature, annually laminated sediments or tree ring chronologies should not suffer from this complications. However, missing data can occur in them as well and it was recently reported that tree-ring based temperature reconstructions might be biased, as trees might be missing rings in exceptionally cold years after volcanic eruptions 33. Carefully cross-dated, such flaws could be identified and corrected for in the final chronology. The final dataset would then, again, be irregular in time.

As they are reconstructed from natural archives with varying sedimentation rates, paleoclimate time series are generally unevenly sampled. They can contain hiatuses and might have poor chronological control. These features require special measures for similarity assessment, as physically meaningful signal reconstruction is often not feasible, and standard interpolation methods introduce strong bias effects 2, 40, 44,51. We have recently shown that using a Gaussian kernel-based correlation estimator, Pearson correlation can be estimated more efficiently than if using interpolation 40. Here, we additionally put forward an algorithm to estimate MI, a nonlinear dependence measure, for unevenly sampled data. In Subsect. 2.2.2 we review these similarity measures and show, that our MI estimation algorithm compares favorably to an approach using standard linear interpolation techniques. All records in one network are required to have recorded climate variability at comparable temporal resolution. For periods of interest in the range of few centuries, annual to multi-annual resolution is required to meet the numerical demands of 
the estimators. Not all records, however, will cover thess3 whole period of interest, and some will display largess4 gaps. While our methodology is able to cope with such 355 complications, individual significance tests for each pair 356 of nodes, mimicking their temporal coverage, have tos57 be conducted. This is in contrast to standard climatesss network construction, where usually a link density se-359 lecting, e.g., the $5 \%$ strongest associations as links is360 used [16, 31,30].

\subsubsection{Similarity measures for irregularly sampled time ${ }^{364}$} series

Linear dependence, or similarity in linear properties ${ }^{367}$ between two time series (i.e. the dynamical processes ${ }^{368}$ behind them) is often estimated employing the $\operatorname{cross}^{369}$ correlation function (XCF) 10,40. The association between observations might, however, also be non-linear ${ }^{370}$ and not follow a specific functional form, which $\operatorname{can}^{371}$ not be captured by linear correlation. Bivariate (cross) $)^{372}$ mutual information as a measure of dependence addi- ${ }^{373}$ tionally captures nonlinear associations [13, which is ${ }^{374}$ why we will use it along with correlation as similarity ${ }^{375}$ functions $S_{i}\left(m \Delta t^{x y}\right)$, with the index $i$ indicating, which ${ }^{376}$ measure was calculated and $m$ representing a lag time $\mathrm{e}^{377}$ step of a width of $\Delta t^{x y}$. We use a lag vector resolution ${ }^{378}$ of $\Delta t^{x y}=\max \left(\Delta t^{x}, \Delta t^{y}\right)$, choosing the larger of the $\mathrm{e}^{379}$ average sampling rates $\Delta t^{x}$ and $\Delta t^{y}$ of the two time ${ }^{380}$ series. The scales of variation of MI and XCF are different, but we do not employ the absolute values in the network analysis. We determine the significance of the numerical estimates with respect to critical values from surrogate data and subsequently convert to a binary scale (0 for no, 1 for significant association) that we can intercompare. Standard methods require regular observation intervals and therefore signal reconstruction on an evenly sampled grid. However, the original irregularity causes positive spectral bias towards low frequencies and consequently high-frequency variability is underestimated when it is overcome by conventional interpolation methods [2,40,44,51]. Gap-filling and meaningful signal reconstruction is non-trivial, as, physically, surrounding climate processes during archive growth (e.g. with sufficient moisture availability) and impeded growth (e.g. in a drought period) are potentially very different and inferring from observations of one on potential observations of the other is probably very error prone. A negative coupling strength bias has been found for the pairwise correlation estimate of irregular time series and linear Pearson correlation can be estimated more efficiently employing a Gaussian kernelbased, adapted, correlation estimator 40 .
Gaussian kernel-based Pearson correlation The main idea of Pearson correlation is to take a mean over concurrently observed and standardized products of observations from time series of stationary stochastic processes. Concurrency of observations is rare for unevenly sampled time series and would need to be forced via signal reconstruction to allow the application of standard methods. Key idea of the Gaussian kernel-based estimator is to calculate a weighted mean over standardized observations, avoiding signal alteration. The Gaussian weights rate, e.g., a product of observations that are (almost) concurrent higher than a product of observations that are far apart. The resultant estimator was tested on synthetic and real datasets and shown to be more efficient for irregular time series than other techniques (e.g. linear interpolation, inversion of the Lomb-Scargle periodogram) [40].

Mutual information for irregularly sampled time series Mutual information $M I(X, Y)$ is a measure of the dependence (linear or nonlinear) between two random variables, $X$ and $Y$. This measure from information theory can be interpreted as the uncertainty reduction in variable $X$, given that we observed $Y$. It is symmetric, i.e. relationships of opposite sign but the same association strength give the same MI. The measure yields a null result if, and only if, the two random variables, in our case time series of observations, are independent 27.

MI can be estimated using

$M I(X, Y)=\sum_{x, y} p_{x, y} \log \frac{p_{x, y}}{p_{x} p_{y}}$,

where $p_{x, y}$ is the two-dimensional joint probability density function of the variables $X$ and $Y$ and $p_{x}$ resp. $p_{y}$ are the one-dimensional probability distributions of $X$ resp. $Y$. Different estimators are applied to estimate mutual information, starting from the joint probability distribution, itself estimated from an $x-y$ scatterplot. In case of irregular sampling, however, the bivariate observations $\left(X_{t}, Y_{t}\right)$ at regular observation points $t$ required for a scatterplot are not readily available. We therefore perform a local reconstruction of the signal, estimating for each point $i\left\{t_{i}^{x}, x_{i}\right\}$ a local signal reconstruction by calculating a weighted mean of signal $\left\{t_{j}^{y}, y_{j}\right\}$, centering the weight around $t_{i}^{x}$. If there are no or too few observations $y_{j}$ available around $t_{i}^{x}$ this reconstruction is not performed. From this we get a new, bivariate set of observations $\left\{t_{i}^{x}, x_{i}, y_{i}^{r e c}\right\}$. We then repeat the procedure by stepping through $t_{j}^{y}$, which yields $\left\{t_{j}^{y}, x_{j}^{r e c}, y_{j}\right\}$. From these sets of observations we can estimate the joint density of $X$ and $Y$ using standard estimators for MI. We have compared the performance 
of MI estimation for standard linear interpolation and $\mathrm{d}_{48}$ our reconstruction scheme at varying sampling irregu-419 larities. We followed the sampling sensitivity analysis420 described in 40. We generated AR1 processes at very421 high time resolution and then re-sampled the observa-422 tions onto the irregular observation times. The driving ${ }_{423}$ process is given by

$X\left(t_{i}\right)=\Phi X\left(t_{i-1}\right)+\xi_{i}$

and we couple a second process to it at a time lag $l$

$Y\left(t_{j}\right)=\alpha X\left(t_{i-l}\right)+\varepsilon_{i}$

$\xi$ and $\varepsilon$ represent Gaussian distributed noise processes, ${ }^{431}$ $\Phi$ represents the prescribed autocorrelation and $\alpha$ the ${ }^{432}$ coupling parameter. Here we chose $\Phi=0.5$ and $\alpha=0.8^{433}$ and, at unit average sampling rate, a time series length ${ }^{434}$ of 250 units. The expected value for mutual informa- ${ }^{435}$ tion of these processes at the lag of coupling is given ${ }^{436}$ by $M I(X(t), Y(t+l))=-0.5 \log \left(1-\rho_{x y}^{2}(l)\right.$, where ${ }^{437}$ $\rho_{x y}(l)=\alpha=0.8$, as the processes follow a bivariate ${ }^{438}$ normal distribution [36]. We can then set out to esti ${ }^{439}$ mate $M I(X(t), Y(t+l))$ from the simulated time se- ${ }^{440}$ ries and, comparing the result to the expected value, ${ }^{441}$ calculate the Root Mean Square Error (RMSE) of the estimators. We show the results in Fig. 2, With increas- ${ }^{443}$ ing sampling irregularity (i.e. larger gaps) the $\mathrm{RMSE}^{444}$ of the linear interpolation routine increases systemati- ${ }^{445}$ cally. This effect is also visible for the Gaussian-kernel ${ }^{446}$ based signal reconstruction, but it is much milder. We ${ }^{447}$ therefore conclude that estimating MI using local Gaus- ${ }^{448}$ sian kernel reconstruction is more efficient than using $^{449}$ standard interpolation.

\subsubsection{Constructing a paleoclimate network}

The adapted similarity measures (Gaussian kernel-based correlation and MI estimation: $g X C F$ and $g M I)$, form f $_{46}$ the basis for a network analysis of paleoclimate records ${ }_{457}$ because employing them we can hope to be able to cap- ${ }_{458}$ ture the true dependence structure with small sampling ${ }_{459}$ bias. Network construction is conducted according $\mathrm{to}_{460}$ the following steps:

1. In the first step, paleoclimate records in the study ${ }^{462}$ region, representing, presumably, one climatic com- ${ }^{463}$ ponent (e.g. monsoonal rainfall amounts) are iden- ${ }^{464}$ tified and checked for comparability: While their ${ }^{465}$ time sampling does not have to be equal, the av- ${ }^{466}$ erage sampling interval should be of the same order of magnitude. Within the time slice of interest, the record should consist of at least 100 observations, to ensure the power of the similarity tests.
2. In the second step we pre-process the suitable datasets. We limit the time series to a time window of width $W$. For each record we subtract a nonlinear trend which we estimate by applying a Gaussian kernel smoother of a bandwidth of $W / 2$. We choose the bandwidth such that we remove centennial-scale trends but do not smooth high-frequency (annual to decadal) variability. The data, within this time window, now has zero mean and unit variance.

3. In the third step, the degree of similarity is estimated for all pairwise combinations of records. Within the overlap of the individual pairs, we calculate lagged MI and Pearson correlation in the 'standard' way, involving interpolation to an average time scale, $i X C F$ and $i M I$, and using the adapted estimators, $g X C F$ and $g M I$. To compensate for possible dating uncertainties, we determine the largest absolute value of the similarity function $S\left(m \Delta t_{x y}\right)$, within time lags of $m=0 \pm 1$ around zero lag. As a result we get four matrices with MI, resp. correlation estimates.

4. We then conduct pairwise significance tests for each similarity measure $S$ as described in [40]: We construct surrogate time series following the null hypothesis that both records are uncoupled irregularly sampled autoregressive processes of order 1 . The persistence time for the test time series is estimated from the original records. The similarity function $S(m)$ for these artificial data is estimated 1000 times, so that the critical values, the 2.5 and $97.5 \%$ quantiles of the distribution of similarity estimates, can be determined.

5. Finally, these critical values are used to threshold the correlation matrices. If a significant correlation exists between the records $i$ and $j$, i.e., $S_{e s t}^{i, j}<S_{2.5}^{i, j}$ or $S_{e s t}^{i, j}>S_{97.5}^{i, j}$, we set $A(i, j)=1$. If no significant similarity is found we set the entry to zero. We repeat this for all four similarity estimators and obtain four adjacency matrices. We then sum the matrices to obtain the final, weighted, adjacency matrix for the network. The nodes $i$ and $j$ are linked, if any $A(i, j)>0$. Link weight scales between zero (no link) and four (all measures find a significant link). Employing $g M I, g X C F$, $i M I$, and $i X C F$ all together we can improve the robustness of the network detection, as then the resulting link weight reflects our certainty of a true similarity and cannot be due to the peculiarity of one measure.

6. The obtained network can now be visualized and analyzed. 


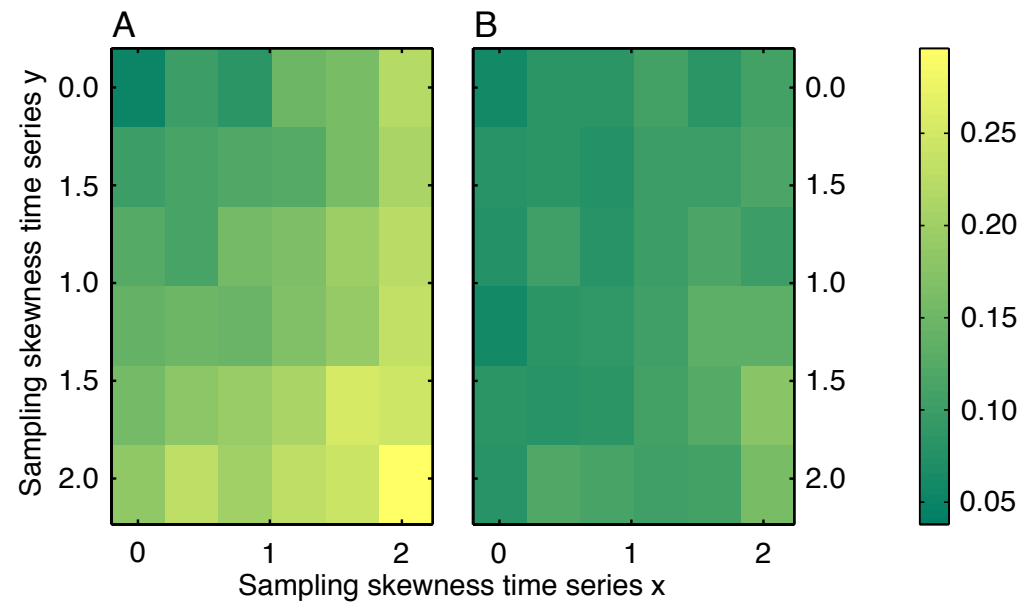

Fig. 2: Evaluation of the MI estimators for irregularly sampled time series. For each patch on the images we generated 100 coupled AR-processes. Signal construction and sampling irregularity of the time series increases along the $\mathrm{x}$ and $\mathrm{y}$ axis (analog to [40]). For each pair of time series we estimated MI, (A) based on interpolation to a mean sampling rate and (B) using an adapted Gaussian kernel scheme (right panel). Colors indicate the RMSE of the estimated cross-MI at the lag of coupling. For the interpolation scheme, a strong trend towards poor performance is clearly visible for increasing sampling irregularity, while the Gaussian-kernel reconstruction scheme still performs much better.

We calculate weighted node degree $D_{i}=\sum_{j} W_{i, j}$, given $n_{95}$ by the sum of link weights $W_{i, j}$ of a node $i$ linking it ${ }_{496}$ to all $j$ others. The overall link density $L$, is given by $y_{497}$ $L=\frac{\sum_{(i, j) W_{i}, j}}{4 N}$, the sum of link weights divided by the possible sum of link weights, depending on the number499 of nodes $N$ and involved similarity measures (here, 4).500 To understand the spatial distribution of our links, wesor define a third measure, PConn, the percentage of re-502 alized connections (PConn) between subdomains. Wesos define it as the fraction of realized vs. possible links504 between nodes west of $95^{\circ}$ longitude (nodes in the tra-505 ditional ISM domain) and nodes east of $95^{\circ}$ longitude. We then generate 1000 random networks, redistributing links randomly (at the adjacency matrix level), and es-506 timate PConn from each. From the resultant distribution of $P C o n n_{\text {sim }}$ we can find the fraction $p$ of random507 networks that show a lower PConn than our observed5os PConn real.

Similarly, we calculate the average link density of all510 nodes and nodes east/west of the boundary to deter-511 mine if they show uniform or differing characteristics. 512 lagmite data as well as one annually laminated sediment core [59, one ice core 54 and one reconstruction of summer temperatures compiled from tree-ring data and historic documents 66]. The data had to cover at least one of the periods ( -30 to 100,100 to 400 or 700 to 1100 years BP) with at least 100 observations.

Tree ring width chronologies (indicated by rwl-crn in Tab. 1) were used as provided, and raw tree ring width series (rwl) were assembled into chronologies by first detrending the individual tree series with a 50year Gaussian kernel smoother (to remove youth bias) standardizing and then averaging the individual trees for the corresponding years.

\section{Results}

We derive small, but due to the spatial and archivespecific heterogeneities still very complex, networks from the datasets in Tab. 1. For each time period (MWP, LIA, late RWP) we select records fulfilling the data requirements described in Subsect. 2.2. We subsequently describe the retrieved networks visually, qualitatively, and quantitatively.

\section{$514 \quad 4.1$ Medieval Warm Period (MWP)}

In our analysis we include published proxy data from the Asian monsoon domain between $66^{\circ}$ and $116^{\circ} \mathrm{E}, 515$ In total, 10 records could be included in the network for and $10^{\circ}$ to $39^{\circ} \mathrm{N}$ (Fig. 1). We include tree-ring and sta-516 the MWP (700-1100 years BP), out of which we had 
Table 1: Table of all paleoclimate records used in this study. Records are listed from West to East. Proxy names marked with asterisks $\left(^{*}\right)$ represent reconstructions of climate parameters. Tree data from China without accompanying reference are available and were downloaded from the ITRDB database at http://www.ncdc.noaa.gov/.

\begin{tabular}{|c|c|c|c|c|c|c|}
\hline No & Name & Lat. $\left[{ }^{\circ} \mathrm{N}\right]$ & Lon. $\left[{ }^{\circ} \mathbf{E}\right]$ & Archive & Proxy & Reference \\
\hline 1 & SO90-39KG-56KA & 25 & 66 & marine & varve thickn. & 59 \\
\hline 2 & Akalagavi & 15 & 74 & stal & $\delta^{18} O$ & 64 \\
\hline 3 & Karakoram & 36 & 75 & tree & *rainfall & 56 \\
\hline 4 & ktrc & 10 & 77 & tree & rwl-crn & 5 \\
\hline 5 & imrf & 13 & 77 & tree & *rainfall & 38 \\
\hline 6 & INDI019 & 30 & 78 & tree & rwl-crn & 4 \\
\hline 7 & INDI021 & 30 & 79 & tree & rwl-crn & 4 \\
\hline 8 & Jhumar & 19 & 82 & stal & $\delta^{18} O$ & 48 \\
\hline 9 & Dandak & 19 & 82 & stal & $\delta^{18} O$ & [3], 48 \\
\hline 10 & DasuopuC3 & 28 & 85 & ice core & $\delta^{18} \mathrm{O}$ & 54 \\
\hline 11 & Wah-Shikar & 25 & 92 & stal & $\delta^{18} O$ & 48 \\
\hline 12 & CHINO06 & 36 & 98 & tree & $\mathrm{rwl}$ & 45 \\
\hline 13 & CHINO05 & 37 & 99 & tree & rwl & 45 \\
\hline 14 & CHIN017 & 29 & 99 & tree & rwl & 12 \\
\hline 15 & CHIN019 & 29 & 100 & tree & rwl & 12 \\
\hline 16 & CHIN021 & 29 & 100 & tree & $\mathrm{rwl}$ & 12 \\
\hline 17 & CHIN001a & 37 & 100 & tree & rwl-crn & noaa-tree-5408; Zu, R.Z. \\
\hline 18 & CHIN018 & 29 & 100 & tree & rwl & 12 \\
\hline 19 & CHINO20 & 30 & 100 & tree & rwl & 12 \\
\hline 20 & CHINOO3 & 38 & 100 & tree & rwl-crn & noaa-tree-5407; Zu, R.Z. \\
\hline 21 & Wanxiang & 33 & 105 & stal & $\delta^{18} \mathrm{O}$ & 68 \\
\hline 22 & Dayu & 33 & 106 & stal & $\delta^{18} \mathrm{O}$ & 52 \\
\hline 23 & VIET001 & 12 & 108 & tree & rwl-crn & 8 \\
\hline 24 & Jiuxian-c996-1 & 33 & 109 & stal & $\delta^{18} O$ & 9 \\
\hline 25 & Heshang & 30 & 110 & stal & $\delta^{18} O$ & 25 \\
\hline 26 & CHIN004ea & 34 & 110 & tree & rwl-crn & noaa-tree- $5352 ; \mathrm{Wu}, \mathrm{X} . \mathrm{D}$ et al. \\
\hline 27 & NCPrecipIndex & 37 & 112 & historic + tree & *JJA precip. & 66 \\
\hline 28 & Shihua 2003 & 39 & 116 & stal & *Temp & 53 \\
\hline
\end{tabular}




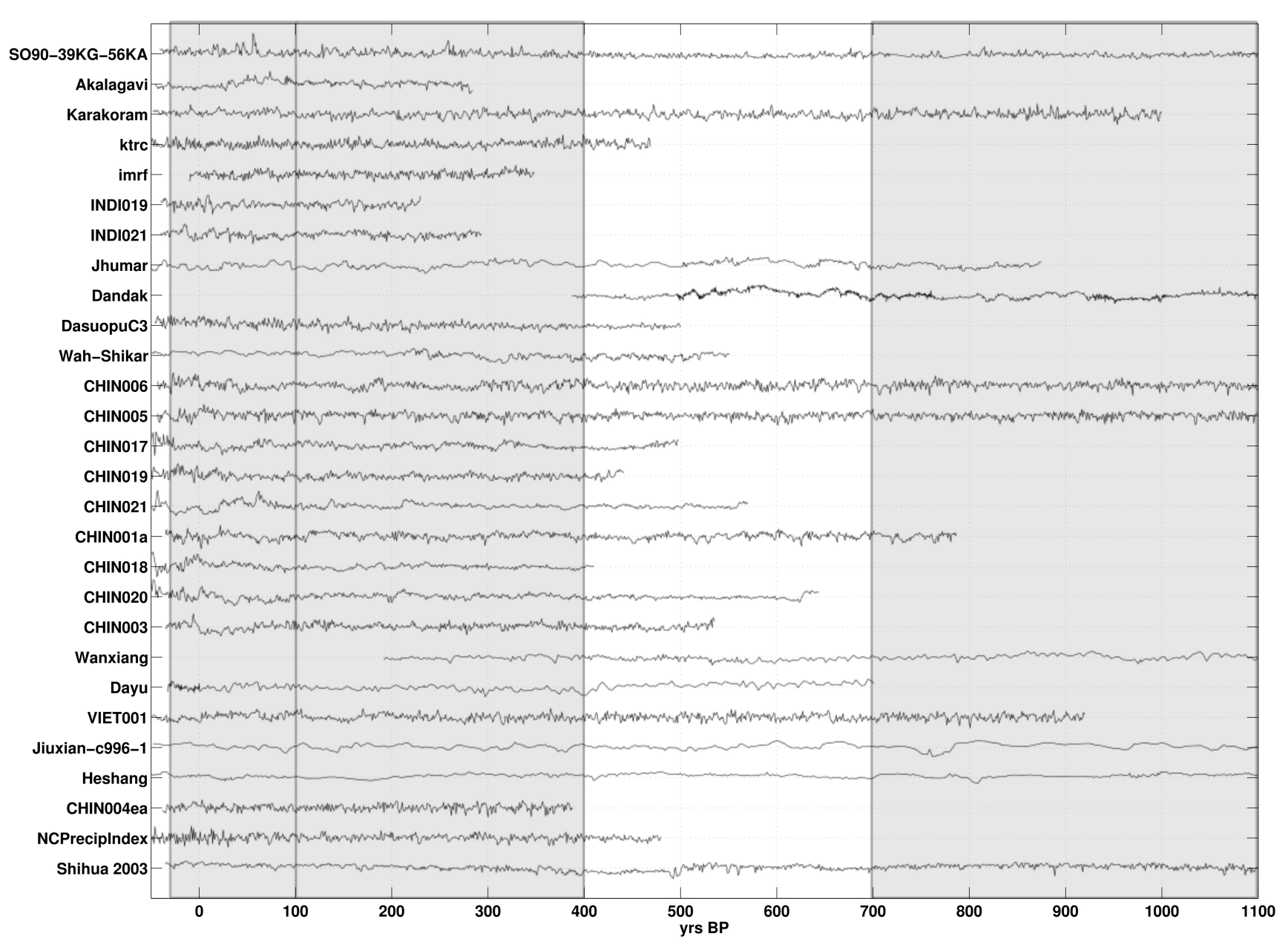

Fig. 3: Temporal coverage of the Asian Monsoon records considered in the paleoclimate networks. While many (22, resp. 25) datasets cover RWP and LIA, we find only 10 records at adequate resolution for the Medieval Warm Period. All data was transformed to zero mean and unit variance for the plot. Shaded areas indicate the time windows studied.

Table 2: Palaeoclimate record composition and results obtained from the networks for the three considered time periods, MWP, LIA and RWP.

\begin{tabular}{|l|l|l|l|}
\hline & MWP & LIA & RWP \\
\hline Time frame $[\mathrm{yrs} \mathrm{BP}]$ & $700-1100$ & $100-400$ & $-30-100$ \\
$\begin{array}{l}\text { No. of records (All/ tree/ stal/ } \\
\text { other) }\end{array}$ & $10(4 / 5 / 1)$ & $25(16 / 6 / 3)$ & $22(16 / 3 / 3)$ \\
No. of records East/West of $\mathbf{9 5}^{\circ} \mathbf{E}$. & $4 / 6$ & $10 / 15$ & $8 / 14$ \\
$\begin{array}{l}\text { Weighted degree } \\
\left(\mathrm{mean} /<95^{\circ} \mathrm{E} />95^{\circ} \mathrm{E}\right)\end{array}$ & $8.00 / 11.25 / 5.83$ & $15.92 / 12.20 / 18.40$ & $11.00 / 9.00 / 12.14$ \\
$\mathbf{P C o n n}(\mathrm{p}-\mathrm{val})$ & $0.24(0.76)$ & $0.14(0.16)$ & $0.13(0.56)$ \\
\hline
\end{tabular}


four tree, five stalagmite and one annually laminateds7o marine record. References to data sources are given in571 Tab. 1. The node distribution is spatially biased, as572 more records are available from longitudes East of $95^{\circ} \mathrm{E}_{573}$ (Tab. 2).

\section{4}

After pairwise similarity assessment and significance testing at the $95 \%$-level, we observe a well-connected network (Fig. 4). Still, the mean correlation levels for ${ }^{575}$ all measures (reported in Tab. 2) are not significantly different from zero (for gXCF and $\mathrm{XXCF}$ ) and the in- ${ }^{576}$ trinsic estimator bias of approximately 0.6 (for $g M I$ and $^{577}$ $i M I)$. Note that though we report the upper and lower ${ }^{578}$ quantiles for MI, we only used the upper quantile to ${ }^{579}$ threshold the Correlation matrix, as MI is a symmetric ${ }^{580}$ measure (see also Subsect. 2.2.2).

Between the 10 nodes we find 22 links, which have ${ }^{582}$ an overall weight of 40 (link weights scale from zero to ${ }^{553}$ four, as described in Subsect. 2.2. . We find two links ${ }^{584}$ with highest certainty (weight $=4$, Wanxiang $\leftrightarrow$ Dandak $^{585}$ and Wanxiang $\leftrightarrow$ Shihua), showing a strong West-East ${ }_{587}^{58}$ connection. The Dandak record is also linked with high ${ }_{588}^{58}$ certainty to Jhumar cave, SO90-39-KG-KA and the tree ring chronology CHIN006). It is the node with the highest weighted degree, followed by the Wanxiang record. The weighted node degree is visualized by the size of ${ }_{502}^{501}$ the nodes in Fig. 4 . The tree-ring record from Viet- ${ }^{592}$ nam, VIET001, is the node with the lowest degree, it ${ }^{593}$ is linked only to one, the easternmost marine record 594 (1). Link weight, in Figs. 4A and 4B, is indicated by $y_{596}^{595}$ both width and darkness of the links. The nodes in ${ }^{596}$ the network in Fig. $4 \mathrm{~B}$ are not placed according to ${ }^{597}$ their geographic origins but according to an iterative ${ }^{598}$ force-weighing algorithm. Linked nodes are attracted ${ }^{599}$ to each other, while nodes without connections are repelled. Isolates, only loosely connected nodes, here the VIET001 or CHIN005 tree ring records, tend to be ${ }^{602}$ pushed to the margins, while hubs, i.e., nodes that are ${ }^{603}$ strongly connected through the network (here: the Dan- ${ }_{605}^{604}$ dak stalagmite record), remain central.

Finally, we divide the nodes into two sections, West and East of $95^{\circ} \mathrm{E}$ and estimate regional degree and $\mathrm{d}_{606}$ PConn, as defined in Subsect. 2.2.4. Were the two domains actually asynchronous and independent, we wouldor not expect to find a significant fraction of realized linksoos between nodes across the artificial border and, by con-609 sequence, PConn to be low. Assuming independencesio of the regions, we would also expect the node degreen11 statistics on both sides to be homogeneous. However,612 at an average weighted degree of 8 we find that nodesors in the West show an almost twice as high degree aso14 further East (Tab. 2). We find PConn $=0.24$, so ap-615 proximately one quarter of the possible links are re-616 alized. Conducting our simple statistical test in which ${ }_{617}$ we redistribute the links randomly across the network for each similarity measure, we find that $76 \%$ of these networks have fewer connections between the subnetworks, so the connectivity across the artificial border is rather high.

\subsection{Little Ice Age (LIA)}

In the more recent period of the LIA (100-400 years $\mathrm{BP})$ we were able to include 25 records, 16 from trees, 6 stalagmite and 3 other records (Records no. 1, 10 and 27, see Tab. 1). Again, the node distribution is spatially biased towards China, with two thirds of the records located east of $95^{\circ} \mathrm{E}$.

108 links connect the nodes, with a weight sum of 199 and a weighted link density of $\approx 17 \%$. We find 5 links of highest and 16 of high certainty (Fig. 5). The 'supernodes', having the highest degree, are th e Chinese stalagmite record, Dayu (sum of weights 27) and the tree chronology, CHIN018 (weight sum 26). The South Indian record of Akalagavi has the lowest link weight sum (5). At the same time, the previously (during the MWP) almost isolated Vietnamese tree-ring record, VIET 00, is now well-connected to the network (weight sum 14) and is with highest certainty associated to tree-ring record CHIN018! In the force-weighted representation (Fig. 5B), however, it is still pushed outwards, similar to the almost isolated Akalagavi record from Southern India.

During the time period of the LIA, the average degree east of the artificial $95^{\circ} \mathrm{E}$ boundary is $30 \%$ higher than on the Indian side of the boundary, while the overall weighted degree is almost twice as high as compared to the MWP. This is concordant with twice the number of available nodes. The estimated PConn is lower (0.14) across the border and relatively few, only $16 \%$, of the randomly generated networks have a lower connectivity.

\subsection{Recent Warm Period (RWP)}

For the RWP (-30-100 years BP, i.e., 1850-1980 AD) we included 22 records, out of which 16 came from trees, three from stalagmites and three from other sources (Number 1, 10 and 27 in Tab. 1). Roughly $60 \%$ of the nodes lie west of $95^{\circ} \mathrm{E}$, the spatial bias is therefore slightly lower than in the preceding time intervals. There is no apparent overall association amongst all nodes, as the mean correlation levels are well between the critical values, given in Tab. 2 .

The obtained network is rather sparsely connected (Fig. 6). We find 62 links between the 22 nodes with an 
A MWP network in geo-coordinates

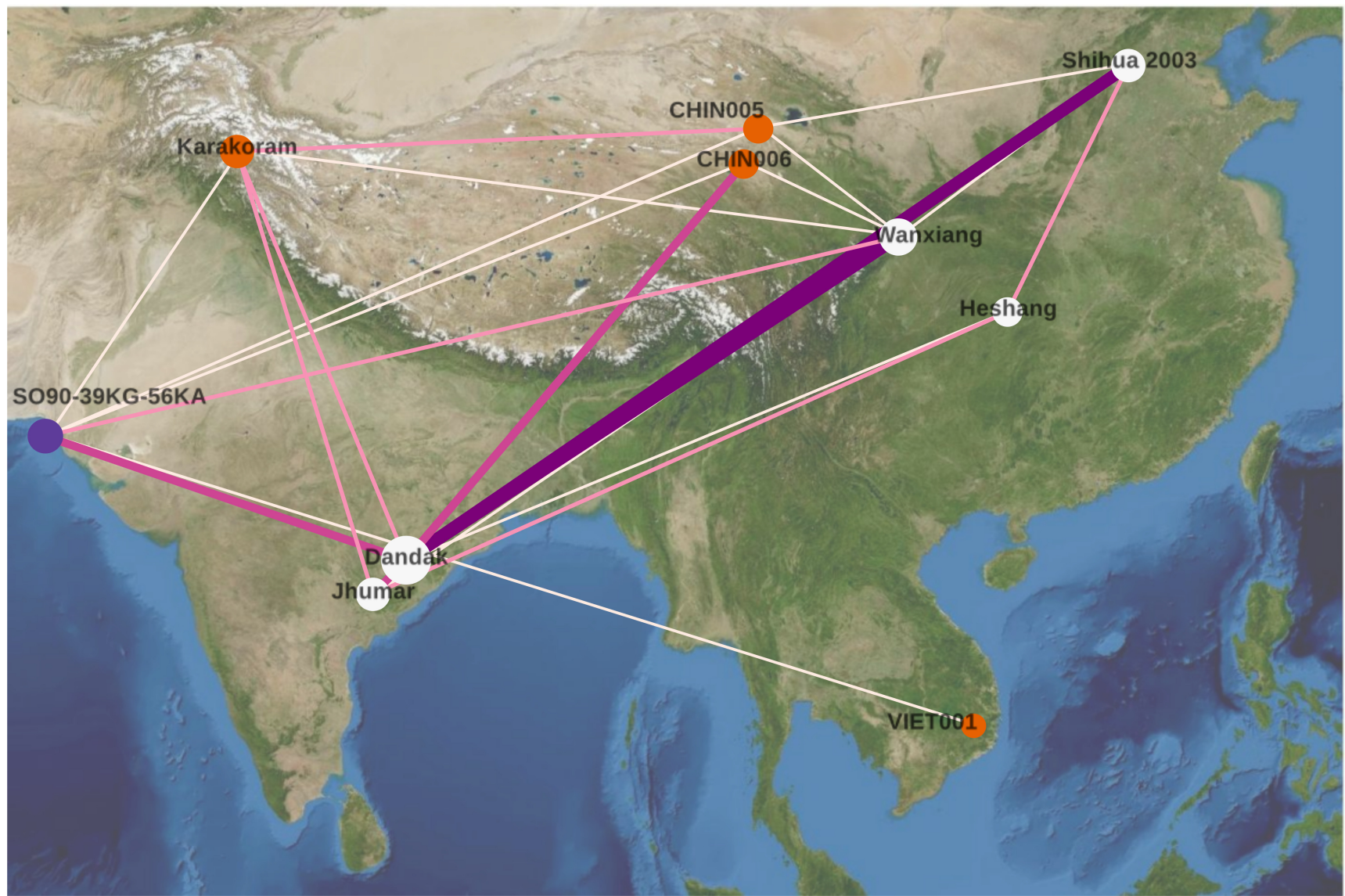

B MWP network force weighted

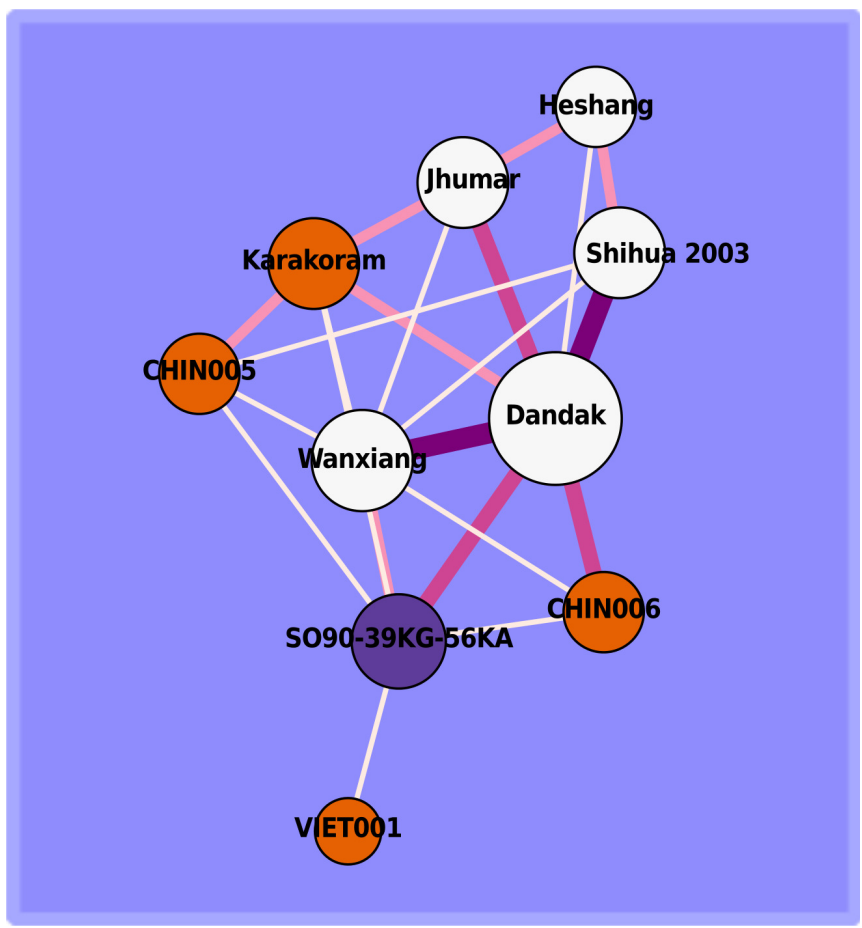

Fig. 4: Network for the MWP: (A) network embedded in the observation space with true geo-coordinates; (B) a force-weighting algorithm was applied in which linked nodes are attracted and unlinked nodes repelled, providing a complimentary network view independent of the nodes' locations. The darker and thicker a link, the higher its weight; the size of a node corresponds to its weigthed node degree, whereas the node color indicates the type of archive (cp. Fig. 1). 
A LIA network in geo-coordinates

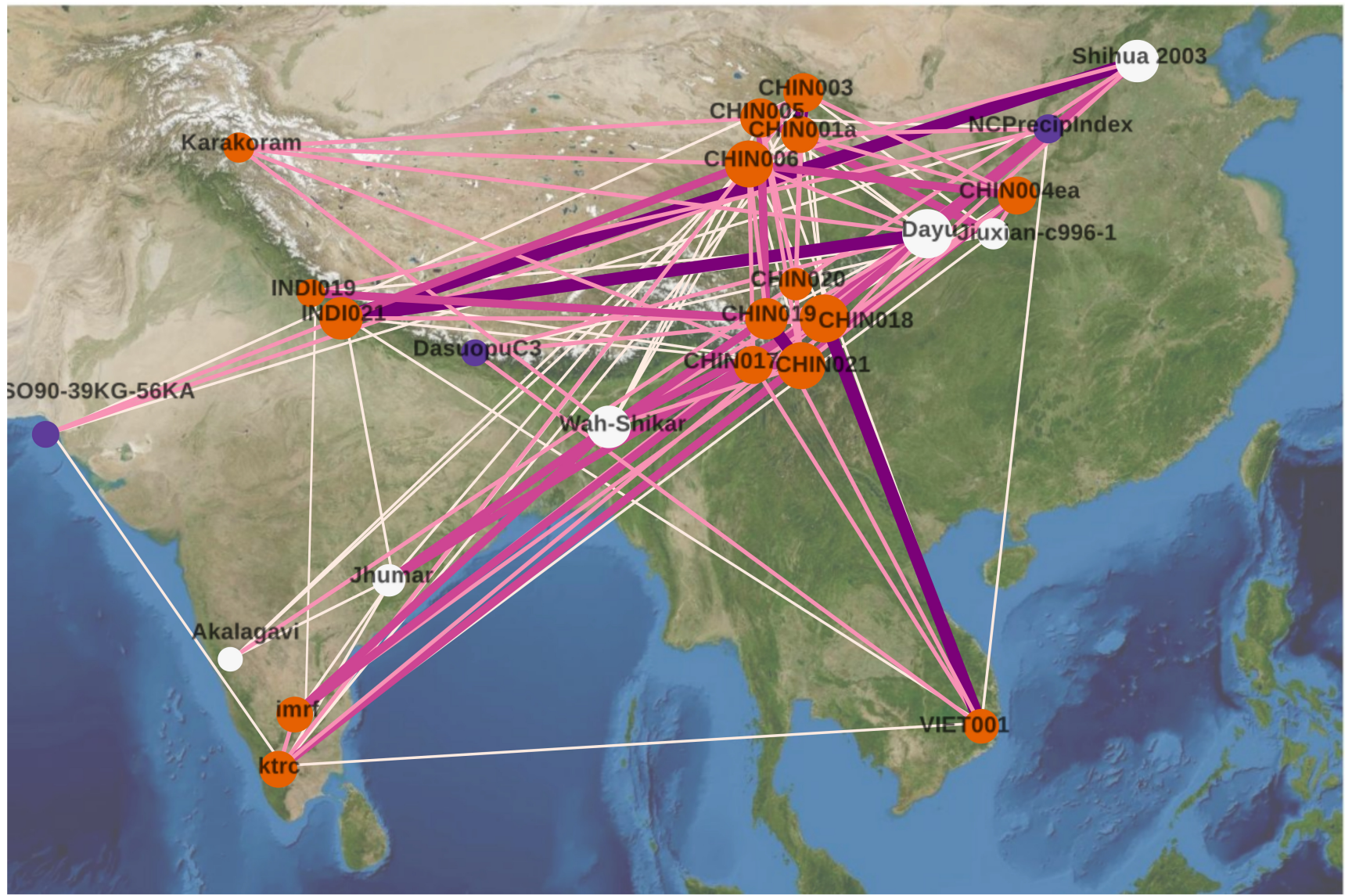

B LIA network force weighted

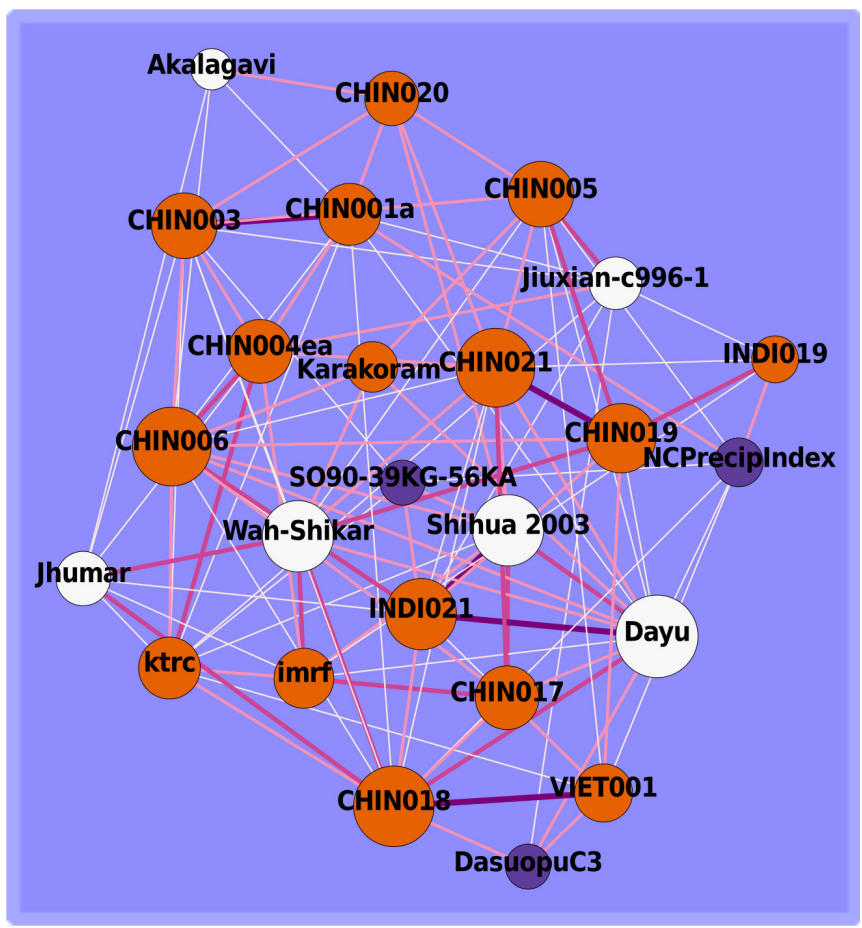

Fig. 5: Network for the LIA: (A) network embedded in the observation space with true geo-coordinates; (B) a force-weighting algorithm was applied in which linked nodes are attracted and unlinked nodes repelled, providing a complimentary network view independent of the nodes' locations. The darker and thicker a link, the higher its weight; the size of a node corresponds to its weigthed node degree, whereas the node color indicates the type of archive (cp. Fig. 1). 
A RWP network in geo-coordinates

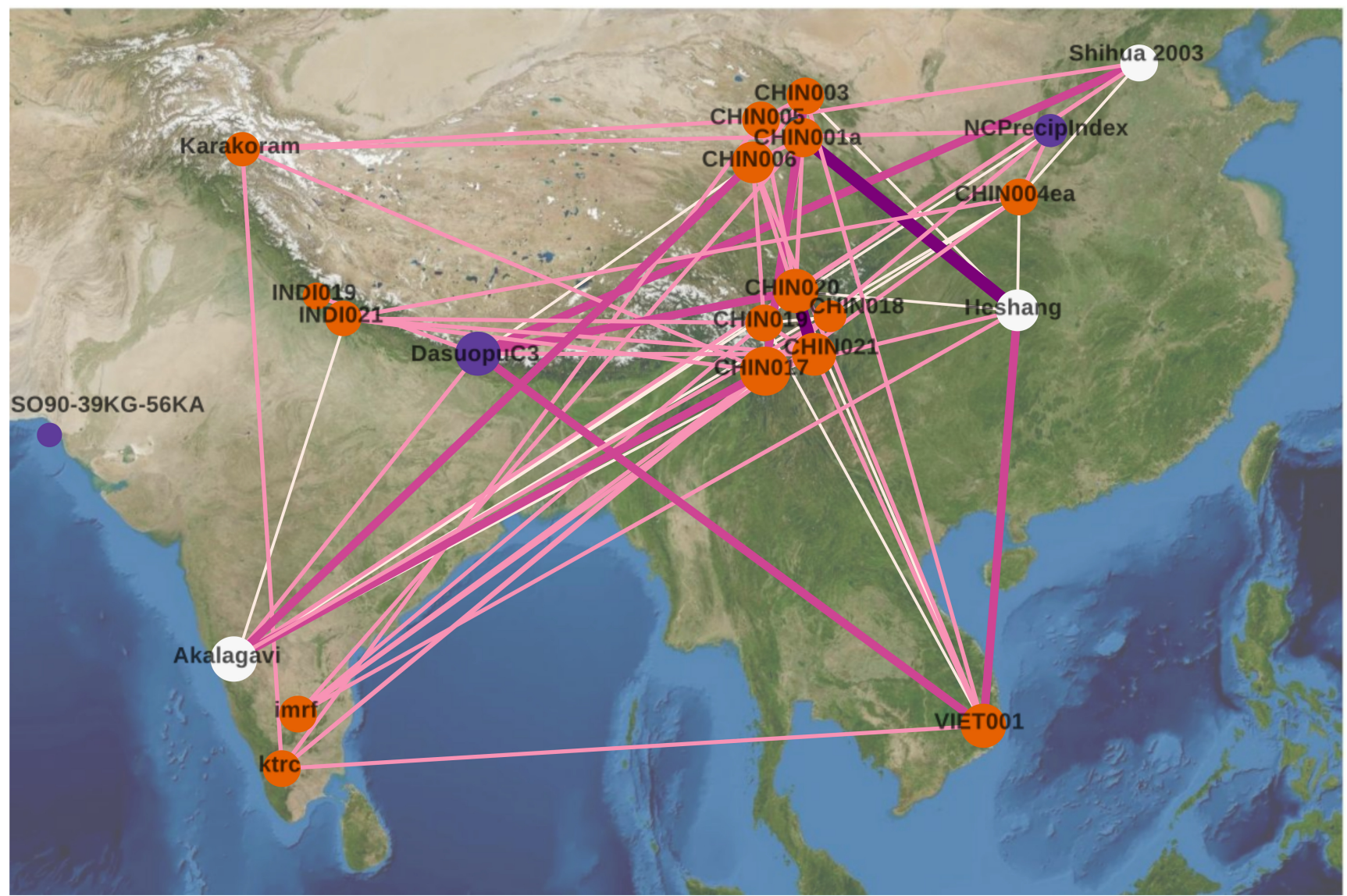

B RWP network force weighted

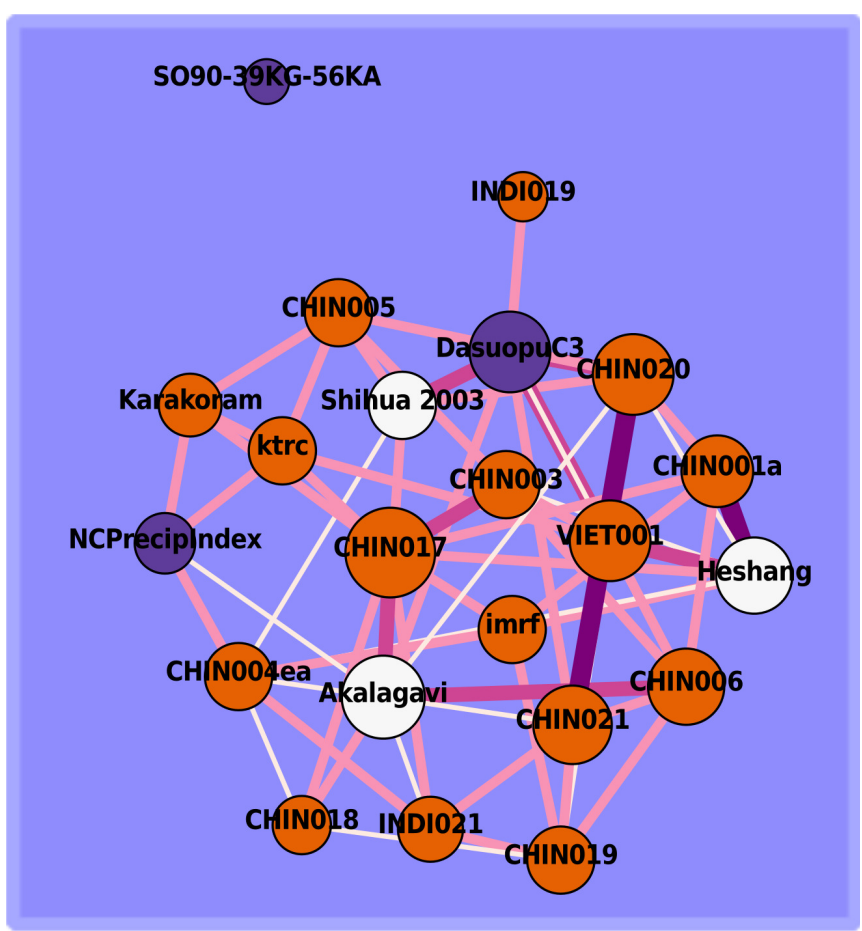

Fig. 6: Network for the RWP: (A) network embedded in the observation space with true geo-coordinates; (B) a force-weighting algorithm was applied in which linked nodes are attracted and unlinked nodes repelled, providing a complimentary network view independent of the nodes' locations. The darker and thicker a link, the higher its weight; the size of a node corresponds to its weigthed node degree, whereas the node color indicates the type of archive (cp. Fig. 1). 
overall link sum of 121. The overall weighted link den-668 sity is $\approx 13 \%$. Only two links of highest certainty ares69 observed (Heshang $\leftrightarrow$ CHIN001a; CHIN021 $\leftrightarrow$ CHIN20)670 and seven of high certainty. The most connected node iso71 the Chinese tree-ring record CHIN017, and the Akala-672 gavi record has the second highest weighted degree (17).673 SO90-39-KG is an isolated node in this time interval,674 with no link to the rest of the network and the Indian675 tree-ring chronology INDI019 has only a weighted degree of 2. VIET001 has an above-average weighted de- ${ }^{676}$ gree (16) and is, like the South Indian Akalagavi record ${ }^{677}$ (17) well-connected to the network, both are centrally ${ }^{678}$ located in the force-weighted network representation ${ }^{679}$ (Fig. 6B).

Although the across-border connectivity PConn is ${ }^{681}$ at 0.13 , lower for the RWP than for the previous LIA ${ }^{682}$ period, the significance of the estimate $(\mathrm{p}=0.54)$ is low $^{683}$ due to the overall lower number of connections (a lower ${ }^{684}$ average degree than in LIA) and the result can not be distinguished from a randomly generated network of the same link density.

4.4 Comparison of Medieval Warm Period, Little Ice Age, and the Recent Warm Period

\section{Summarizing the above results we find that}

- the warmer MWP featured a high overall link den-692 sity, a strong West-East connection and a higher ${ }^{693}$ node degree west of the artificial boundary.

- the colder LIA showed an lower link density, a lowero95 West-East linkage and a higher degree east of $95^{\circ} \mathrm{E}^{696}$ longitude. Within the ISM domain, fewer links con-697 nect meridionally than zonally.

- during the relatively warmer RWP we derive the ${ }^{69}$ lowest overall link density and a medium West-East700 connectivity, consistent with a more uniform net-701 work.

- although the net connectivity PConn is decreas-703 ing towards the present $(0.24,0.14,0.13)$ for $\mathrm{MWP} / 704$ LIA/ RWP, this is consistent with an decrease in link density $(0.22,0.17,0.13)$. If we account for this 505 effect by standardizing the fraction of realized zonalioo edges by dividing by the average link density, weror observe a pattern that is in accordance with theros significance test results: $P$ Conn $/ D \approx(1.1,0.8,1.0)_{709}$ is high 1000 years ago, drops for the period of ther10 LIA and is higher, though not at the MWP level, forn1 the most recent RWP network. In compliance with ${ }_{712}$ this, the $p$-values we obtained show the same pat-713 terns, $(0.76,0.16,0.54)$. These $p$-values indicate how 714 $P C o n n$ is to be interpreted with respect to the nulli15 hypothesis of the network being homogeneous and 716 random. The high value of $p$ during the MWP points towards a stronger zonal linkage than expected from random graphs of the same link density. The low value for the LIA reflects a lower connectivity, which is inconsistent with an overall association between the areas east and west. The RWP network is practically random $(p=0.54$, close to the median of the $P C o n n$ from surrogate networks).

The mean correlation level in the time section, considering all pairwise similarities, is close to to the zero, resp. the bias level for MI (results not shown). We would like to point out that, although we do have a shift towards a higher fraction from tree-ring records towards today, the average tree-link density is slightly higher but comparable to the link densities observed amongst the rest of the nodes for LIA and RWP (see Tab. 22) and much lower for the MWP.

\section{Discussion and Conclusions}

Medieval Warm Period The MWP paleoclimate network, representing a period of northern hemispheric warmth, shows strong zonal connectivity between the subdomains, linking India and China very effectively. This strong eastward flow of dynamical information indicates a strong ISM circulation, with a strong ISM penetration into the mainland of China. A temperature modulation of ISM strength has been observed on decadal to millennial timescales $9,68,60,11$ and is expected from model results 42 . Increased northern hemisphere temperature could have allowed an earlier retreat of the Tibetan High in spring parallel to a more northward intrusion of the ITCZ. This could then have resulted in an earlier ISM onset, and a prolonged and enhanced ISM season. We hypothesize that increased circulation allowed deeper eastward ISM penetration into China, and that the northern ITCZ is the main factor linking India and China during the MWP summers.

Little Ice Age In contrast to the MWP, the cool LIA yields a comparably weaker information flux towards the East and strong regional associations within China, pointing towards increased regional scale, or EASM, influence in this region. The low number of meridional links over India during the LIA and the disconnection between the ASM sub-systems could be explained if we invoke a southward mean ITCZ position, leading to a relative strengthening of local weather effects in India and China, and a disruption of the link between the ISM and EASM domains. At the same time the Vietnamese tree-ring record is now strongly connected to sites in 
central China, and we find highly significant links across 69 the Tibetan Plateau. A relative increase in the Tibetanzo High and an increased importance of local effects dur-771 ing this cold phase would explain these observations.772 In agreement with this the (at present ISM-dominated) 773 $^{2}$ record from Wanxiang cave 9] was found to show ar74 wetter MWP and RWP with stronger, and a drier LIA 775 with weaker monsoon periods, respectively. A link be-776 tween the Indian Dandak cave record, located centrallyzr in the zonal ISM inflow corridor, and Wanxiang caverz was observed for the onset phase of the LIA [3,40. Un-779 fortunately, we have no insight in this link during therso entire LIA period because the Dandak record does not781 fully cover the LIA. However, for the Jhumar stalagmiters2 record, which is located in close proximity to the Dan-783 dak site, we do not find highly significant multi-annualrs4 to decadal scale similarities during the LIA period, cor-785 roborating our hypothesis of a weakened teleconnectionzo between India and China at that time.

Recent Warm Period The paleoclimate network for the ${ }^{789}$ most recent time period does neither indicate strong ${ }^{790}$ nor weak zonal information flow. Link orientation ap ${ }^{791}$ pears to be almost random, which could be consistent ${ }^{792}$ with a transition from the 'cold state' (emphasized $\mathrm{Ti}^{-}{ }^{793}$ betan High and local effect importance, and decreased ISM meridional components) to a 'warm, MWP-like,794 state' (deep eastward ISM penetration, strong merid-795 ional links within India). This is also supported by nodego6 degree statistics, which show an equal distribution of f $_{97}$ links on both sides of the artificial $95^{\circ} \mathrm{E}$ boundary. Our ${ }_{798}$ observation period does, however, include the transi-799 tion from the LIA 37] and increasing anthropogenic800 impacts and alteration of the atmosphere, also in mon-801 soonal Asia [41,68, and we must be careful not to over-802 interpret this results.

Though the quantitative accordance between thesos two warmer periods is striking, the low spatio-temporaloo6 resolution of the MWP proxies is a potential source of $f_{807}$ uncertainty. While we strove to ensure comparabilityвoв by sampling all regions in both networks, archive com-8o9 position becomes tree-oriented toward the present. Al-s10 though a source of uncertainty, the bias should be neg-811 ligible, because the tree-specific link densities are not,812 or little, higher than for the rest of the archives. Thisser could be due to the fact that the tree-sites we included,814 especially those in Central China, are located in moun-815 tainous areas, where strong geographic heterogeneitiess16 in form of valleys and mountains induce local moisture 817 flow divergences.

The low number of available paleoclimate proxy reconds from the late Holocene is the reason why we choses2o to combine temperature and precipitation-dominated records, based on the assumption of a functional relationship between the parameters. If a sufficient number of datasets representing variability of one climate parameter across the Asian monsoon domain is available, we could attempt to reconstruct physical flows as in more recent climate network analysis [16, 30, but at present such an analysis, at least for sub-decadal to decadal scale variability, is not feasible in the ASM domain. On decadal to centennial time scales, such an analysis might, however, be feasible with the inclusion of other terrestrial and marine archives (e.g. pollen, coral, or lacustrine records). Our study focused on the Asian monsoon, but it is equally possible - and informative - to use available paleoclimate records from other locations in addition to study the regional response to forcing factors like the North Atlantic Oscillation, or El Niño Southern Oscillation (ENSO). Future extensions of this method may consider directionalities and indirect couplings, e.g., derived from recurrence based methods [17,70]. Furthermore, it would be informative to use the new method for time intervals during interstadial, stadial, and interglacial times. Such study could shed light on the variability of, e.g., monsoonal teleconnections during these periods.

Discussion of the paleoclimate network approach The paleoclimate network approach is a potentially very powerful tool to complement the currently mostly visuallybased paleoclimate data interpretation. While it is possible to compare a few records by eye (performing socalled 'wiggle matching'), this becomes more difficult when the number of datasets grows. Indeed, the similarity between some of the time series in Fig. 3 is obvious (e.g. between the Dandak and Jhumar $\delta^{18} O$ time series), but the advantage of the paleoclimate network approach is that we obtain figures for the degree of similarity, not only concerning the relationship between two proxy records, but also its ties to all other records included in the analysis. Therefore, to address the question ("How did the subsystems interact during the different time periods?") we were able to compute a connectivity index from realized links connecting the subdomains. The results indicate that interaction was stronger during the MWP than during the LIA, and the recent warming finds more MWP-like conditions. Contemplating the time series in Fig 3 by eye alone we could not possibly have come to such a similar conclusion.

Uncertainties of the records should be incorporated into similarity assessment wherever possible. This can be done, for example by comparing, visually or numerically, on an absolute time scale 7], where the dating 
errors are moved into the proxy domain and the timest5 scale becomes certain. Provided with a proxy record ${ }^{376}$ with confidence bounds it is possible to incorporate these uncertainties into the paleoclimate network approach numerically (i.e. via Monte Carlo simulations).

A basic prerequisite for this, however, is the access to ${ }_{678}$ dating information for all data that should be included, ${ }^{879}$ a requirement not met at the moment.

More generally, a paleoclimate network is a tool that ${ }_{882}^{881}$ enables us to obtain a spatio-temporal fingerprint of thess climate system, a visual representation that summa ${ }^{884}$ rizes what we can see by eye - and more. We could us ${ }_{886}^{885}$ it also to study proxy response to climate parameter\$887 be they linear or nonlinear 1,43, as it relies on asso-888 ciation measures suitable for irregular sampling. Simi ${ }^{889}$ larly, weather station data is often riddled with gaps ${ }_{891}^{890}$ making it necessary to reconstruct these missing datas92 - or cut the time periods to the sections of overlap. ${ }^{893}$ To compare them amongst each other - and to proxy $y^{894}$ reconstructions - Gaussian kernel-based correlation es ${ }^{8956}$ timation [40] and mutual information are well-suited.997 Such a systematic validation could, for example, take $e^{898}$ place in the framework of interacting networks [14], ${ }_{900}^{899}$ in a potential multivariate extension of the paleoclimate $e_{901}$ networks.

We have attempted to reconstruct monsoonal $\mathrm{dy}_{-}{ }^{903}$ namics of the last millennium using a combination of $f_{905}^{904}$ different paleoclimate archives and proxies from Asia.906 Using a paleoclimate network approach we find that the ${ }^{07}$ warm climate of the Medieval Warm Period was char ${ }^{908}$ acterized by a strong zonal ISM penetration into China,910 whereas during the cold Little Ice Age the meridionalo11 component within the EASM was strengthened. We hy ${ }^{912}$ pothesize that the ITCZ (itself responding on a variety ${ }_{914}^{913}$ of factors) is the major influencing factor connecting the $\mathrm{g}_{15}$ two sub-systems of the Asian monsoon domain during16 warm intervals. During cold periods, the Tibetan High $^{917}$ would have forced a retreat of the ITCZ and local effect ${ }_{919}^{918}$ become more dominant. Though we can, at present, not $_{920}$ make a statement about the future of the ISM strength, ${ }^{221}$ we find that the most recent period (1850 to $1980 \mathrm{AD})_{923}^{922}$ is dynamically more similar to the MWP than to the ${ }_{924}$ LIA. by the the German Federal Ministry of man Science Foundation (DFG research group FOR 1380 "Hi-931 malaya: Modern and Past Climates (HIMPAC))", the DFG932 graduate school GRK 1364 "Shaping Earth's Surface in a933 Variable Environment") and the Schweizer National Fond934 (SNF Sinergia grant CRSI22 132646/1). The authors would935 like to thank M. Yadava, R. Ramesh and H. Borgaonkar forg36 providing data from India as well as G. Helle and M. Freund937 for helpful discussions about tree-ring data. Software to ana-938 lyze irregularly sampled time series using the methods in this paper can be found on http://tocsy.pik-potsdam.de

\section{References}

1. Anchukaitis, K.J., Evans, M.N., Kaplan, A., Vaganov, E.A., Hughes, M.K., Grissino-Mayer, H.D., Cane, M.A.: Forward modeling of regional scale tree-ring patterns in the southeastern United States and the recent influence of summer drought. Geophysical Research Letters 33(4), $2-5$ (2006). DOI 10.1029/2005GL025050

2. Babu, P., Stoica, P.: Spectral analysis of nonuniformly sampled data - a review. Digital Signal Processing 20(2), 359-378 (2010). DOI 10.1016/j.dsp.2009.06.019

3. Berkelhammer, M., Sinha, A., Mudelsee, M., Cheng, H., Edwards, R.L., Cannariato, K.: Persistent multidecadal power of the Indian Summer Monsoon. Earth and Planetary Science Letters 290(1-2), 166-172 (2010). DOI 10.1016/j.epsl.2009.12.017

4. Borgaonkar, H., Pant, G., Rupa Kumar, K.: Dendroclimatic reconstruction of summer precipitation at Srinagar, Kashmir, India, since the late-eighteenth century. The Holocene 4(3), 299-306 (1994). DOI 10.1177/ 095968369400400309

5. Borgaonkar, H., Sikder, A., Ram, S., Pant, G.: El Niño and related monsoon drought signals in 523-year-long ring width records of teak (Tectona grandis L.F.) trees from south India. Palaeogeography, Palaeoclimatology, Palaeoecology 285(1-2), 74-84 (2010). DOI 10.1016/j. palaeo.2009.10.026

6. Breitenbach, S.F., Adkins, J.F., Meyer, H., Marwan, N., Kumar, K.K., Haug, G.H.: Strong influence of water vapor source dynamics on stable isotopes in precipitation observed in Southern Meghalaya, NE India. Earth and Planetary Science Letters 292(1-2), 212-220 (2010). DOI 10.1016/j.epsl.2010.01.038

7. Breitenbach, S.F.M., Rehfeld, K., Goswami, B., Baldini, J.U.L., Ridley, H.E., Kennett, D., Prufer, K., Aquino, V.V., Asmerom, Y., Polyak, V.J., Cheng, H., Kurths, J., Marwan, N.: Constructing proxy-record age models (copra). Climate of the Past Discussions 8, 1-40 (2012). DOI 10.5194/cpd-8-1-2012

8. Buckley, B.M., Anchukaitis, K.J., Penny, D., Fletcher, R., Cook, E.R., Sano, M., Nam, L.C., Wichienkeeo, A., Minh, T.T., Hong, T.M.: Climate as a contributing factor in the demise of Angkor, Cambodia. Proceedings of the National Academy of Sciences of the United States of America 107(15), 6748-52 (2010). DOI 10.1073/pnas. 0910827107

9. Cai, Y., Tan, L., Cheng, H., An, Z., Edwards, R.L., Kelly, M.J., Kong, X., Wang, X.: The variation of summer monsoon precipitation in central China since the last deglaciation. Earth and Planetary Science Letters 291(14), 21-31 (2010). DOI 10.1016/j.epsl.2009.12.039

10. Chatfield, C.: The analysis of time series: an introduction, 6th edn. CRC Press, Florida, US (2004)

11. Cheng, H., Zhang, P.Z., Spötl, C., Edwards, R.L., Cai, Y.J., Zhang, D.Z., Sang, W.C., Tan, M., An, Z.S.: The climatic cyclicity in semiarid-arid central Asia over the past 500,000 years. Geophysical Research Letters 39(1), 1-5 (2012). DOI 10.1029/2011GL050202

12. Cook, E.R., Anchukaitis, K.J., Buckley, B.M., D'Arrigo, R.D., Jacoby, G.C., Wright, W.E.: Asian monsoon failure and megadrought during the last millennium. Science (New York, N.Y.) 328(5977), 486-9 (2010). DOI 10.1126/ science. 1185188 
13. Dionisio, A., Menezes, R., Mendes, D.A.: Mutual infort005 mation: a measure of dependency for nonlinear time set006 ries. Physica A: Statistical Mechanics and its Applicał007 tions 344(1-2), 326-329 (2004). DOI 10.1016/j.physatoos 2004.06.144

1009

4. Donges, J.F., Schultz, H.C., Marwan, N., Zou, Y.1010 Kurths, J.: Investigating the topology of interacting netto11 works. The European Physical Journal B 84, 635-651012 (2011). DOI 10.1140/epjb/e2011-10795-8

1013

5. Donges, J.F., Zou, Y., Marwan, N., Kurths, J.: Com ${ }_{\mathrm{T} 014}$ plex networks in climate dynamics. European Physi I015 cal Journal-Special Topics 174, 157-179 (2009). DOI ${ }_{1016}$ 10.1140/epjst/e2009-01098-2

16. Donges, J.F., Zou, Y., Marwan, N., Kurths, J. The back bone of the climate network. EPL (Europhysics Letters, , $_{019}$ 87(4), 48,007 (2009). DOI 10.1209/0295-5075/87/48007 $7_{1020}$

17. Feldhoff, J.H., Donner, R.V., Donges, J.F., Marwan, N.ro21 Kurths, J.: Geometric detection of coupling directions by $\mathrm{y}_{022}$ means of inter-system recurrence networks. Physics Let T023 ters A (subm.)

18. Gadgil, S.: T He I Ndian M Onsoon and I Ts V Ariability ${ }^{1024}$ Annual Review of Earth and Planetary Sciences 31(1) 429-467 (2003). DOI 10.1146/annurev.earth.31.100901 141251

19. Ge-Li, W., Tsonis, A.A.: A preliminary investigation ${ }_{1029}^{1028}$ on the topology of Chinese climate networks. Chinese Physics B 18(11), 5091-5106 (2009)

20. Gozolchiani, A., Havlin, S., Yamasaki, K.: Emergence of ${ }^{1031}$ El Niño as an Autonomous Component in the Climate ${ }_{1033}^{1032}$ Network. Physical Review Letters 107(14), 1-5 (2011) $)_{1034}^{1033}$ DOI 10.1103/PhysRevLett.107.148501

21. Gupta, A.K.: Solar influence on the Indian summer mon- ${ }^{-1035}$ soon during the Holocene. Geophysical Research Letters 32(17), 2-5 (2005). DOI 10.1029/2005GL022685

22. Gupta, A.K., Anderson, D.M., Overpeck, J.T.: Abrupt changes in the Asian southwest monsoon during the ${ }^{1039}$ Holocene and their links to the North Atlantic Ocean ${ }^{1040}$ Nature 421(6921), $354-7$ (2003). DOI $10.1038_{1042}^{\text {i041 }}$ nature 01340

23. Herzschuh, U.: Palaeo-moisture evolution in monsoonal ${ }^{1043}$ Central Asia during the last 50,000 years. Quaternary Science Reviews 25(1-2), 163-178 (2006). DOI 10.1016 ${ }^{1045}$ j.quascirev.2005.02.006

24. Hong, Y., Hong, B., Lin, Q., Zhu, Y., Shibata, Y., Hirota ${ }^{1047}$ M., Uchida, M., Leng, X., Jiang, H., Xu, H., Wang, H., ${ }^{1048}$ Yi, L.: Correlation between Indian Ocean summer mon-1049 soon and North Atlantic climate during the Holocene. ${ }^{1050}$ Earth and Planetary Science Letters 211(3-4), 371-381051 (2003). DOI 10.1016/S0012-821X(03)00207-3

1052 5. Hu, C., Henderson, G., Huang, J., Xie, S., Sun, Y., John-1053 son, K.: Quantification of Holocene Asian monsoon rain-1054 fall from spatially separated cave records. Earth and $d^{055}$ Planetary Science Letters 266(3-4), 221-232 (2008). DO1056 10.1016/j.epsl.2007.10.015

26. Jones, P.D., Osborn, T.J., Briffa, K.R.: The evolution o1058 climate over the last millennium. Science (New York ${ }^{1059}$ N.Y.) 292(5517), 662-7 (2001). DOI 10.1126/science 1060 1059126

27. Kraskov, A., Stögbauer, H., Grassberger, P.: Estimat1062 ing mutual information. Physical Review E 69(6), 1-16063 (2004). DOI 10.1103/PhysRevE.69.066138

28. Kumar, K.K., Kamala, K., Rajagopalan, B., Hoerling1,065 M.P., Eischeid, J.K., Patwardhan, S.K., Srinivasan, G.1066 Goswami, B.N., Nemani, R.: The once and future pulse ofo67 Indian monsoonal climate. Climate Dynamics 36(11-12) $)_{1068}$ 2159-2170 (2010). DOI 10.1007/s00382-010-0974-0 1069
29. Ma, Z.B., Cheng, H., Tan, M., Edwards, R.L., Li, H.C., You, C.F., Duan, W.H., Wang, X., Kelly, M.J.: Timing and structure of the Younger Dryas event in northern China. Quaternary Science Reviews 41, 83-93 (2012). DOI 10.1016/j.quascirev.2012.03.006

30. Malik, N., Bookhagen, B., Marwan, N., Kurths, J.: Analysis of spatial and temporal extreme monsoonal rainfall over South Asia using complex networks. Climate Dynamics (2011). DOI 10.1007/s00382-011-1156-4

31. Malik, N., Marwan, N., Kurths, J.: Spatial structures and directionalities in Monsoonal precipitation over South Asia. Nonlinear Processes in Geophysics 17(5), 371-381 (2010). DOI 10.5194/npg-17-371-2010

32. Managave, S.R., Sheshshayee, M.S., Bhattacharyya, A., Ramesh, R.: Intra-annual variations of teak cellulose $\delta 18 \mathrm{O}$ in Kerala, India: implications to the reconstruction of past summer and winter monsoon rains. Climate Dynamics 37(3-4), 555-567 (2010). DOI 10.1007/ s00382-010-0917-9

33. Mann, M.E., Fuentes, J.D., Rutherford, S.: Underestimation of volcanic cooling in tree-ring-based reconstructions of hemispheric temperatures. Nature Geoscience 5(3), 202-205 (2012). DOI 10.1038/ngeo1394

34. May, W.: The sensitivity of the Indian summer monsoon to a global warming of $2^{\circ} \mathrm{C}$ with respect to pre-industrial times. Climate Dynamics 37(9-10), 1843-1868 (2010). DOI 10.1007/s00382-010-0942-8

35. Mayewski, P.a., Rohling, E.E., Curt Stager, J., Karlén W., Maasch, K.a., David Meeker, L., Meyerson, E.a., Gasse, F., van Kreveld, S., Holmgren, K., Lee-Thorp, J., Rosqvist, G., Rack, F., Staubwasser, M., Schneider, R.R., Steig, E.J.: Holocene climate variability. Quaternary Research 62(3), 243-255 (2004). DOI 10.1016/j.yqres.2004. 07.001

36. Nazareth, D., Soofi, E., Zhao, H.: Visualizing Attribute Interdependencies Using Mutual Information, Hierarchical Clustering, Multidimensional Scaling, and Selforganizing Maps. 2007 40th Annual Hawaii International Conference on System Sciences (HICSS'07) pp. 53-53 (2007). DOI 10.1109/HICSS.2007.608

37. Osborn, T.J., Briffa, K.R.: The spatial extent of 20thcentury warmth in the context of the past 1200 years. Science (New York, N.Y.) 311(5762), 841-4 (2006). DOI 10.1126/science.1120514

38. Pant, G., Kumar, K.R., Borgaonkar, H.: Statistical models of climate reconstruction using tree ring data. Proc. Indian Natn. Sci. Acad. 54(3), 354-364 (1988)

39. Ramesh, R., Tiwari, M., Chakraborty, S., Managave, S.R., Yadava, M.G., Sinha, D.K.: Retrieval of south Asian monsoon variation during the Holocene from natural climate archives. Current Science 99(12), 1170-1786 (2010)

40. Rehfeld, K., Marwan, N., Heitzig, J., Kurths, J.: Comparison of correlation analysis techniques for irregularly sampled time series. Nonlinear Processes in Geophysics 18(3), 389-404 (2011). DOI 10.5194/npg-18-389-2011

41. Ruddiman, W.F.: The anthropogenic greenhouse era began thousands of years ago. Climatic Change 61, 261-293 (2003)

42. Schewe, J., Levermann, A., Cheng, H.: A critical humidity threshold for monsoon transitions. Climate of the Past 8(2), 535-544 (2012). DOI 10.5194/cp-8-535-2012

43. Schleser, G.H., Helle, G., Lu, A., Vos, H.: Isotope signals as climate proxies: the role of transfer functions in the study of terrestrial archives. Quaternary Science Reviews 18, 927-943 (1999) 
44. Schulz, M., Stattegger, K.: SPECTRUM: spectral analy ${ }_{137}$ sis of unevenly spaced paleoclimatic time series. Com+138 puters \& Geosciences 23(9), 929-945 (1997). DOI 1139 10.1016/S0098-3004(97)00087-3

45. Sheppard, P.R., Tarasov, P.E., Graumlich, L.J., Heusst141 ner, K.U., Wagner, M., Sterle, H., Thompson, L.G.: An+142 nual precipitation since $515 \mathrm{BC}$ reconstructed from livt143 ing and fossil juniper growth of northeastern Qinghail14 Province, China. Climate Dynamics 23(7-8), 869-881 145 (2004). DOI 10.1007/s00382-004-0473-2

46. Shukla, R.P., Tripathi, K.C., Pandey, A.C., Das, I.: Pre P147 diction of Indian summer monsoon rainfall using Niñ@148 indices: A neural network approach. Atmospheric $\mathrm{Re}_{\mathrm{r} 149}$ search 102(1-2), 99-109 (2011). DOI 10.1016/j.atmosres:150 2011.06.013

7. Singh, J., Yadav, R.R., Wilmking, M.: A 694-year 152 tree-ring based rainfall reconstruction from Himachad $1_{53}$ Pradesh, India. Climate Dynamics 33(7-8), 1149-115\$ 154 (2009). DOI 10.1007/s00382-009-0528-5

48. Sinha, A., Cannariato, K.G., Stott, L.D., Cheng, H., $\operatorname{Ed}^{1155}$ wards, R.L., Yadava, M.G., Ramesh, R., Singh, I.B.: A A $_{157}$ 900-year (600 to 1500 A.D.) record of the Indian summer ${ }_{158}$ monsoon precipitation from the core monsoon zone of $f_{159}$ India. Geophysical Research Letters 34(16), 1-5 (2007)r160 DOI 10.1029/2007GL030431

49. Sinha, A., Stott, L., Berkelhammer, M., Cheng, H., $\operatorname{Ed}^{1161}$ wards, R.L., Buckley, B., Aldenderfer, M., Mudelsee, M.ri163 A global context for megadroughts in monsoon Asia dur $\mathrm{r}_{1164}$ ing the past millennium. Quaternary Science Review\$165 30(1-2), 47-62 (2011). DOI 10.1016/j.quascirev.2010.10 $10_{1166}$ 005

50. Steinhaeuser, K., Chawla, N.V., Ganguly, A.R.: Complex Networks as a Unified Framework for Descriptive Analy ${ }_{\overline{1169}}$ sis and Predictive Modeling in Climate Science. Scienc9. ${ }_{170}$ And Technology (2010). DOI 10.1002/sam.10100 1171 51. Stoica, P., Sandgren, N.: Spectral analysis of irregularly ${ }_{\overline{1}_{172}}$ sampled data: Paralleling the regularly-sampled data ${ }_{173}$ approaches. Digital Signal Processing 16(6), 712-734 (2006). DOI 10.1016/j.dsp.2006.08.012

52. Tan, L., Cai, Y., Cheng, H., An, Z., Edwards, R.L.: Sum ${ }^{1175}$ mer monsoon precipitation variations in central China $a_{177}$ over the past 750 years derived from a high-resolution ${ }_{178}$ absolute-dated stalagmite. Palaeogeography, Palaeocli $\mathrm{i}_{\overline{1} 79}$ matology, Palaeoecology 280(3-4), 432-439 (2009). DOI ${ }_{180}$ $10.1016 /$ j.palaeo.2009.06.030

53. Tan, M., Liu, T.: Cyclic rapid warming on centennial ${ }_{1182}^{1181}$ scale revealed by a 2650-year stalagmite record of warm season temperature. Geophysical Research Letter ${ }_{184}$ 30(12) (2003). DOI 10.1029/2003GL017352

54. Thompson, L.G., Yao, T., Mosley-Thompson, E., Davis ${ }_{1186}^{1185}$ M., Henderson, K., Lin, P.N.: A High-Resolution Millen ${ }_{1187}^{1186}$ nial Record of the South Asian Monsoon from Himalayan Ice Cores. Science 289(September), 1998-2001 (2000) ${ }_{1189}^{1188}$

55. Trenberth, K.E.: Relationships between precipitation ${ }_{1190}^{1189}$ and surface temperature. Geophysical Research Letters 32(14), 2-5 (2005). DOI 10.1029/2005GL022760

56. Treydte, K.S., Schleser, G.H., Helle, G., Frank, D.C. ${ }_{r 193}^{1192}$ Winiger, M., Haug, G.H., Esper, J.: The twentieth cen $_{1194}^{1193}$ tury was the wettest period in northern Pakistan over ${ }_{195}^{1194}$ the past millennium. Nature 440(7088), 1179-82 (2006) $)_{1196}^{1195}$ DOI $10.1038 /$ nature 04743

57. Tsonis, A.A., Swanson, K.L.: Topology and Predictabil ${ }_{1198}^{1197}$ ity of El Niño and La Niña Networks. Physical Review Letters 100, 228,502 (2008). DOI 10.1103/PhysRevLett. 100.228502

58. Tsonis, A.a., Swanson, K.L., Roebber, P.J.: What Do Networks Have to Do with Climate? Bulletin of the
American Meteorological Society 87(5), 585-595 (2006) DOI 10.1175/BAMS-87-5-585

59. Von Rad, U., Schaaf, M., Michels, K., Schulz, H., Berger, W., Sirocko, F.: A 5000-yr Record of Climate Change in Varved Sediments from the Oxygen Minimum Zone off Pakistan, Northeastern Arabian Sea. Quaternary Research 51(1), 39-53 (1999). DOI 10.1006/qres.1998.2016

60. Wang, P., Clemens, S., Beaufort, L., Braconnot, P., Ganssen, G., Jian, Z., Kershaw, P., Sarnthein, M.: Evolution and variability of the Asian monsoon system: state of the art and outstanding issues. Quaternary Science Reviews 24(5-6), 595-629 (2005). DOI 10.1016/j.quascirev. 2004.10.002

61. Wang, Y., Cheng, H., Edwards, R.L., He, Y., Kong, X., An, Z., Wu, J., Kelly, M.J., Dykoski, C.a., Li, X.: The Holocene Asian monsoon: links to solar changes and North Atlantic climate. Science (New York, N.Y.) 308(5723), 854-7 (2005). DOI 10.1126/science. 1106296

62. Wang, Y., Liu, X., Herzschuh, U.: Asynchronous evolution of the Indian and East Asian Summer Monsoon indicated by Holocene moisture patterns in monsoonal central Asia. Earth-Science Reviews 103(3-4), 135-153 (2010). DOI 10.1016/j.earscirev.2010.09.004

63. Wang, Y.J., Cheng, H., Edwards, R.L., An, Z.S., Wu, J.Y., Shen, C.C., Dorale, J.A.: A high-resolution absolute-dated late Pleistocene Monsoon record from Hulu Cave, China. Science (New York, N.Y.) 294(5550), 2345-8 (2001). DOI 10.1126/science.1064618

64. Yadava, M., Ramesh, R., Pant, G.: Past monsoon rainfall variations in peninsular India recorded in a 331-year-old speleothem. The Holocene 14(4), 517-524 (2004). DOI 10.1191/0959683604hl728rp

65. Yamasaki, K., Gozolchiani, A., Havlin, S.: Climate Networks Based on Phase Synchronization Analysis Track El-Niño. Progress of Theoretical Physics Supplement 179(179), 178-188 (2009). DOI 10.1143/PTPS.179.178

66. Yi, L., Yu, H., Ge, J., Lai, Z., Xu, X., Qin, L., Peng, S.: Reconstructions of annual summer precipitation and temperature in north-central China since $1470 \mathrm{AD}$ based on drought/flood index and tree-ring records. Climatic Change 110(1-2), 469-498 (2011). DOI 10.1007/ s10584-011-0052-6

67. Zhang, J., Chen, F., Holmes, J.a., Li, H., Guo, X., Wang, J., Li, S., Lü, Y., Zhao, Y., Qiang, M.: Holocene monsoon climate documented by oxygen and carbon isotopes from lake sediments and peat bogs in China: a review and synthesis. Quaternary Science Reviews 30(15-16), 19731987 (2011). DOI 10.1016/j.quascirev.2011.04.023

68. Zhang, P., Cheng, H., Edwards, R.L., Chen, F., Wang, Y., Yang, X., Liu, J.J., Tan, M., Wang, X., An, C., Dai, Z., Zhou, J., Zhang, D., Jia, J., Jin, L., Johnson, K.R.: A test of climate, sun, and culture relationships from an 1810-year Chinese cave record. Science 322(5903), 940-2 (2008). DOI 10.1126/science.1163965

69. Zhou, T., Li, B., Man, W., Zhang, L., Zhang, J.: A comparison of the Medieval Warm Period, Little Ice Age and 20th century warming simulated by the FGOALS climate system model. Chinese Science Bulletin 56(28-29), 30283041 (2011). DOI 10.1007/s11434-011-4641-6

70. Zou, Y., Romano, M.C., Thiel, M., Marwan, N., Kurths, J.: Inferring Indirect Coupling by Means of Recurrences. International Journal of Bifurcation and Chaos 21(4), 1099-1111 (2011). DOI 10.1142/S0218127411029033 